\title{
Spectrum, Pattern, and Clinical Outcomes of Adult Emergency Department Admissions in Selected Hospitals of Western Ethiopia: A Hospital-Based Prospective Study
}

\author{
Ashenafi Habte Woyessa $\left(\mathbb{D},{ }^{1}\right.$ Birhanu Yadecha Dibaba, ${ }^{2}$ Getahun Fetensa Hirko, ${ }^{2}$ \\ and Thanasekaran Palanichamy ${ }^{3}$ \\ ${ }^{1}$ Wollega University, Institute of Health Science, School of Nursing and Midwifery, \\ Department of Emergency and Critical Care Nursing, Nekemte, Ethiopia \\ ${ }^{2}$ Wollega University, Institute of Health Science, School of Nursing and Midwifery, Department of Nursing, Nekemte, Ethiopia \\ ${ }^{3}$ Wollega University, Institute of Health Science, School of Nursing and Midwifery, Department of \\ Psychiatry Nursing, Nekemte, Ethiopia
}

Correspondence should be addressed to Ashenafi Habte Woyessa; ashexman2019@gmail.com

Received 26 April 2019; Revised 8 July 2019; Accepted 18 July 2019; Published 6 August 2019

Academic Editor: Selim Suner

Copyright (C) 2019 Ashenafi Habte Woyessa et al. This is an open access article distributed under the Creative Commons Attribution License, which permits unrestricted use, distribution, and reproduction in any medium, provided the original work is properly cited.

Background. There has been a steady rise in the absolute number of emergency room admissions over the last few decades. The healthcare delivery system of a country is required to be adjusted to patterns of morbidity and mortality to mitigate the minimized prolonged ill health consequences and premature death of adults. The spectrum, patterns, morbidity, and mortality of health and health-related emergency conditions for which patients visit hospitals often reflect the magnitude of different health problems in a society. The objective of this study was therefore to assess the spectrum, pattern, characteristics, and clinical outcomes of emergency department admissions among adult people who visited EDs of the selected hospitals in western Ethiopia. Methodology. Hospitalbased prospective cross-sectional study design was utilized. To select hospitals to be included in the study, the area sampling technique was used. Five administrative zones in west Oromia were selected as geographical clusters. Then, four hospitals were randomly selected from each zone. Finally, the consecutive sampling technique was utilized to recruit the study participants. Results. The mean age of the patients admitted to emergency departments (EDs) of the selected hospitals was 34.98 years. The male-to-female ratio of the respondents was nearly equal $(1: 1.04)$. While one-fourth $(20.4 \%)$ of the patients arrived by ambulances (without identifying reason), $23.6 \%$ of them visited the emergency department as they had no other place to go. Medical emergencies (45.4\%) were the leading types of emergencies followed by traumatic emergencies (27.3\%). Respiratory distress (12.43\%), extremity fractures (9.61\%), and hypertensive disorders (8.6\%) were among the top leading causes of adult ED admissions. Vital signs were deranged in about $59.4 \%$ of the cases. The most common type of immediately life-threatening problems identified on arrival was impairment of breathing (37\%), followed by circulatory compromises (30\%). Emergency department admission patterns were variable with peak admissions in the month of February and the lowest in November. The vast majority (90.9\%) of emergency patients survived. While $8.5 \%$ of patients died of the various types of emergency conditions, the final clinical outcome was not identified in $1.5 \%$ of the patients. Conclusion. This study has showed mixed cases with varied patterns and outcomes of adult emergency department admissions. As overall there is a need to be alert during specific seasons, actions must be taken to improve the readiness of existing emergency room services. Furthermore, it is worthwhile to invest further on standardizing and organizing prehospital services at the community level. 


\section{Introduction}

The health of adults in sub-Saharan Africa is becoming increasingly important priority in global health policy. There has been constant increase in the absolute number of emergency admissions for defined populations over the last three decades. Adult mortality, death between the ages of 15 and 60, is 4 to 40 times higher in sub-Saharan Africa than in developed countries $[1,2]$.

The causes of morbidity and/or mortality in sub-Saharan Africa regions are predicted to undergo a significant shift towards endemic noncommunicable diseases. A gradual change in lifestyle and improvement of socioeconomic status of the third world countries are causing substantial changes on the previously recognized public health problems. Public violence including violence to women is also becoming important causes of emergency department visits. Moreover, poorly organized emergency medical service system where prehospital services are totally lacking in several places calls for considering modifications of the adapted healthcare delivery system. In other words, the healthcare delivery system of a country must be adjusted to patterns of morbidity and mortality to mitigate and minimize consequences of prolonged ill health and premature death of adults $[3,4]$.

Information related to the spectrum and patterns of emergency conditions for which clients visit the emergency departments and their clinical outcomes often indicates the actual magnitude of different health problems in a community. Furthermore, such information are essential in healthcare planning and provision of essential health services including key resources like equipment, hospital space, and other logistics [5-9].

However, very little or probably nothing has been known about the spectrum, pattern, characteristics, and clinical outcomes of local-community emergency problems for which they visit emergency rooms in Ethiopia. The objective of this study was therefore to assess the spectrum, pattern, characteristics, and clinical outcomes of emergency department admissions among adult people who visited EDs of the selected hospitals which ultimately contribute to works done to reduce the ever-growing mortality and complications secondary to emergencies.

\section{Materials and Methods}

2.1. Study Setting. This study was conducted in three zones of Wollega, located in the western part of Oromia regional state, western Ethiopia. Four zonal hospitals with a similar level of services were randomly selected from these zones: Nekemte Referral Hospital from East Wollega Zone, Gimbi and Nejo Hospitals from West Wollega Zone, and Shambu Hospital from Horo Guduru Wollega Zone. The study was carried out from February, 2017 to June 2017 among adult patients who have visited the selected hospitals for all forms of emergency conditions.

2.1.1. Methods. Hospital-based prospective cross-sectional study was employed to assess the pattern, spectrum, characteristics, and clinical outcomes of adult emergency department admissions in the selected hospitals.

\subsubsection{Sample Size Determination and Sampling Procedure.} Since the objective of the study was to determine the spectrum, patterns, and clinical outcomes of adult emergency department visits during a specified study period, no specific sampling size determination was employed. The area sampling technique was used to select the zones in which the hospitals are found. Five administrative zones, namely, Buno, Kelem Wollega, West Wollega, East Wollega, and Horo Guduru Wollega zones were selected as geographical clusters from the western Oromia region. Out of them, three zones (West Wollega, East Wollega, and Horo Guduru Wollega) were randomly selected. Then, the four mentioned hospitals were randomly included in the study. Finally, all adult patients with all forms of emergency problems who have visited and were treated in emergency departments of the respective hospitals during the study period were consecutively included.

2.1.3. Inclusion Criteria. All adult patients who have visited the ED of the selected hospitals for all emergency conditions during the study period were included.

2.1.4. Exclusion Criteria. All patients of less than 18 years old and who were critical and unconscious patients with no attendants were excluded.

2.1.5. Research Tool and Data Collection Techniques. Data were collected using comprehensively organized and pretested interviewer-administered questionnaires. The tool was adopted from up-to-date literature $[2,3,5,6,10,11]$. Necessary modifications were made to the tool so that it was specific, reliable, and valid enough to answer the research questions and meet the study objectives. The questionnaire was composed of four parts (sociodemographic characteristics of the patients, baseline clinical information, spectrum, pattern of visits, and Emergency Department visit outcomes). Eight data collectors (two for each hospital) were recruited. In order to familiarize them with collection of the required data and upholding the confidentiality, training was given by investigators.

2.1.6. Data Quality Control. Initial tool prepared in English was translated to local language (Afan Oromo) and translated back to English by respective language experts. Before conducting the main study, pretest was carried out in one nonselected hospital. Based on the findings of the pretest, necessary modifications were made to the tool. In addition, investigators have closely supervised the data collection process and necessary corrections were considered on all data collection sites. Moreover, the collected data were checked again for completeness before data entry. All incomplete data found were discarded. The cleaning process was performed by running simple frequency after data entry 
for its consistency. Further check has been done for inconsistency by referring the hard copy of the questionnaires.

2.2. Data Processing and Analysis. After data collection, the already coded questionnaires were checked for completeness. Data were initially entered into EpiData version 3.2 by data clerks after several steps of check for completeness and accuracy. Then, the entered data were exported to SPSS program version 20 for data analysis. Descriptive statistics was generated for spectrum, characteristics, patterns, and clinical outcomes emergency department admissions. Finally, the results of the study were presented using text, tables, charts, and graphs.

\section{Result}

A total of 952 adult patients presented to the emergency departments of the selected four hospitals in western Ethiopia and who met the inclusion criteria were involved in the study. As incomplete questionnaires were discarded, data obtained from 889 respondents were analyzed, making the response rate $93.3 \%$. The key findings related to sociodemographic characteristics, baseline clinical information, spectrum and forms of ED admissions, leading causes of adult ED admission, and final outcome of adult ED admissions are presented in the subsequent sections.

3.1. Sociodemographic Characteristics of the Patients. The mean $(+\mathrm{SD})$ age of the patients admitted to adult emergency department of the hospitals was $34.98(+15)$ years. The male to female ratio of adult emergency department admissions was nearly equal $(1: 1.04)$ (Table 1$)$.

3.2. Baseline Clinical Characteristics of the Patients. This study has identified the baseline clinical characteristics of patients and reasons of emergency room visit. Out of total respondents, more than half $(51.9 \%)$ of the patients were presented to the EDs as self-referral, whereas the remaining patients were referred to the hospitals from other health facilities. It was their first visit to the ED of the selected hospitals for over three-fourth $(76.9 \%)$ of the patients. While levels of consciousness in about $10 \%$ of emergency patients were not determined, $127(14.3 \%)$ of patients arrived unconscious. Vital signs were deranged in about $59.4 \%$ of the cases (Table 2).

3.3. Reasons of Emergency Department Visits. The study also explored respondents' relevant reasons of emergency room visits. While only one-fourth (20.4\%) of them arrived by ambulance or other emergency vehicles, only 40 (4.5\%) of them visited the ED because they believe that they get most of care at the emergency room (Table 3 ).

3.4. Patterns and Spectrum of Emergency Department Admission. In this study, the number of adult ED admissions per month was variable with peak admissions in the month of February and the lowest in the month of November (Figure 1).

As to the spectrum and forms of adult ED admissions, $45.4 \%$ of the patients were of medical emergency in their types. Traumatic emergency (27.3\%) and surgical emergency (15.9\%) took the 2nd and 3rd ranks, respectively (Figure 2).

3.5. Nature of Emergency Department Admissions. Findings regarding the leading causes of adult emergency department admission at the selected hospitals revealed that a respiratory distress $(12.43 \%)$, extremity fractures (9.61\%), and hypertensive disorders $(8.6 \%)$ were among the top leading causes of adult ED admissions (Figure 3).

Specific medical emergencies as leading causes of adult emergency room admissions were separately identified in this study. Shock of different causes, unconsciousness of different causes, respiratory distress, DM complications (DKA and hypoglycemia), nonspecified acute febrile illnesses, and serious forms of tuberculosis were among the top leading causes of ED admissions in the selected hospitals during this specified study period (Table 4).

Among the injuries presented, extremity fracture, organophosphate poisoning, and road traffic accident were among the leading causes of ED admissions in the selected hospitals. Impairment of breathing (37\%) and circulatory compromises $(30 \%)$, the two most common types of lifethreatening problems, identified immediately on arrival (Table 5).

3.6. Clinical Outcomes and Duration of Hospital Stay. The final clinical outcome of emergency department admissions in terms of death, survival, and length of hospital stay was one aim of this study. While the large majority (90.9\%) of them survived, the final outcome was not identified in about $1.5 \%$ of the patients. Overall, among all patients who visited emergency departments in the study period, about $8.5 \%$ (2.5\% arrived dead, $6.4 \%$ died in the emergency departments, and the remaining $1.6 \%$ died after ward/ICU admission) (Figure 4).

Regarding the patients' duration of hospital stay, more than half $(58.2 \%)$ cases stayed in respective hospitals for $1-3$ days. The rest of $41.8 \%$ have stayed in the hospitals for 4-7 days.

\section{Discussion}

A number of studies revealed that there has been a consistent increase in the absolute number of emergency department admissions rate for defined population over the last decade. The key findings of this study related to pattern, characteristics, baseline clinical information, spectrum of emergency department admissions, leading causes of emergency department admission, and outcome of adult emergency department (ED) admissions of this study are compared and contrasted with currently existing literatures and presented briefly.

The mean age of the patients admitted to adult ED of the hospitals during the study period was 34.98 years. The adult 
TABle 1: Distribution of respondents by their socio-demographic characteristics in Nekemte, western Ethiopia, 2017.

\begin{tabular}{|c|c|c|c|c|}
\hline No. & Variables $(N=889)$ & Category & Frequency & Percent \\
\hline \multirow{6}{*}{1} & \multirow{6}{*}{ Age of the patient } & $15-24$ & 243 & 27.31 \\
\hline & & $25-34$ & 215 & 24.20 \\
\hline & & $35-44$ & 201 & 22.62 \\
\hline & & $45-54$ & 127 & 14.30 \\
\hline & & $55-64$ & 63 & 7.10 \\
\hline & & +65 & 40 & 4.54 \\
\hline \multirow[b]{2}{*}{2} & \multirow{2}{*}{ Sex } & Male & 503 & 56.60 \\
\hline & & Female & 386 & 43.41 \\
\hline \multirow{4}{*}{3} & \multirow{4}{*}{ Marital status } & Single & 273 & 30.70 \\
\hline & & Married & 542 & 61.02 \\
\hline & & Divorced & 46 & 5.20 \\
\hline & & Widowed & 28 & 3.10 \\
\hline \multirow{4}{*}{4} & \multirow{4}{*}{ Level of education attained } & No schooling & 257 & 28.92 \\
\hline & & Primary (grade 1-6) & 247 & 27.81 \\
\hline & & Secondary (grade 7-12) & 247 & 27.80 \\
\hline & & Tertiary (>grade 12) & 138 & 15.50 \\
\hline \multirow{7}{*}{5} & \multirow{7}{*}{ Monthly income } & $150-500$ & 485 & 54.59 \\
\hline & & $500-750$ & 117 & 13.20 \\
\hline & & $750-1500$ & 54 & 6.13 \\
\hline & & $1500-3,000$ & 83 & 9.30 \\
\hline & & $3000-5000$ & 53 & 6.05 \\
\hline & & +5000 & 55 & 6.20 \\
\hline & & Unknown & 42 & 4.70 \\
\hline \multirow{2}{*}{6} & \multirow{2}{*}{ Residence } & Town & 396 & 44.50 \\
\hline & & Rural & 493 & 55.50 \\
\hline \multirow{7}{*}{7} & \multirow{7}{*}{ Occupation } & Government employee & 111 & 12.50 \\
\hline & & Maid/servant & 34 & 3.80 \\
\hline & & Merchant & 133 & 15.07 \\
\hline & & Farmer & 351 & 39.50 \\
\hline & & Laborer & 30 & 3.40 \\
\hline & & Driver & 82 & 9.22 \\
\hline & & No formal job & 148 & 16.71 \\
\hline
\end{tabular}

TABLe 2: Distribution of emergency patients by their baseline information, Nekemte, Ethiopia, 2017.

\begin{tabular}{|c|c|c|c|c|}
\hline No. & Baseline information $(N=889)$ & Category & Frequency & Percent \\
\hline \multirow{6}{*}{1} & \multirow{6}{*}{ Mode of arrival } & By people/shoulder & 65 & 7.30 \\
\hline & & Public transportation & 346 & 38.91 \\
\hline & & Ambulance & 282 & 31.72 \\
\hline & & Private car & 134 & 15.11 \\
\hline & & On foot & 59 & 6.48 \\
\hline & & Horse back & 3 & 0.30 \\
\hline \multirow{2}{*}{2} & \multirow{2}{*}{ Treatment given before arrival } & Yes & 266 & 29.81 \\
\hline & & No & 623 & 70.10 \\
\hline \multirow{5}{*}{3} & \multirow{5}{*}{ Source of referral } & Self & 461 & 51.90 \\
\hline & & Public health center & 304 & 34.22 \\
\hline & & Other public hospitals & 37 & 4.22 \\
\hline & & Private health facility & 38 & 4.30 \\
\hline & & Other & 49 & 5.51 \\
\hline \multirow{5}{*}{4} & \multirow{5}{*}{ Living condition } & Alone & 44 & 4.90 \\
\hline & & With family & 763 & 85.80 \\
\hline & & With friends & 51 & 5.70 \\
\hline & & On the street & 14 & 1.61 \\
\hline & & Other & 17 & 1.90 \\
\hline
\end{tabular}


TABle 2: Continued.

\begin{tabular}{|c|c|c|c|c|}
\hline No. & Baseline information $(N=889)$ & Category & Frequency & Percent \\
\hline \multirow{3}{*}{5} & \multirow{3}{*}{ Number of visit } & First & 684 & 76.90 \\
\hline & & Repeated & 202 & 22.70 \\
\hline & & Unknown & 3 & 0.30 \\
\hline \multirow{3}{*}{6} & \multirow{3}{*}{ Arrival time } & Weekend & 96 & 10.81 \\
\hline & & Night & 135 & 15.10 \\
\hline & & Day & 658 & 74.10 \\
\hline \multirow{4}{*}{7} & \multirow{4}{*}{$\begin{array}{l}\text { Time between arrival and initiation of treatment in } \\
\text { minutes }\end{array}$} & $<15$ & 662 & 74.50 \\
\hline & & $15-30$ & 166 & 18.71 \\
\hline & & $30-60$ & 48 & 5.42 \\
\hline & & $>60$ & 13 & 1.50 \\
\hline \multirow{4}{*}{8} & \multirow{4}{*}{ Who brought the patient } & Self & 475 & 53.40 \\
\hline & & Friend & 300 & 33.70 \\
\hline & & Family member & 109 & 12.32 \\
\hline & & Police & 5 & 0.60 \\
\hline \multirow{3}{*}{9} & \multirow{3}{*}{ Vital signs on arrival } & Normal & 348 & 39.11 \\
\hline & & Deranged & 528 & 59.42 \\
\hline & & Not taken & 13 & 1.51 \\
\hline \multirow{4}{*}{10} & \multirow{4}{*}{ Level of consciousness on arrival } & Conscious & 404 & 45.41 \\
\hline & & Subconscious & 268 & 30.14 \\
\hline & & Unconscious & 127 & 14.33 \\
\hline & & Not evaluated & 90 & 10.22 \\
\hline \multirow{3}{*}{11} & \multirow{3}{*}{ Presence of known chronic illness } & Yes & 259 & 29.10 \\
\hline & & No & 591 & 66.55 \\
\hline & & Unknown & 39 & 4.40 \\
\hline \multirow{6}{*}{12} & \multirow{6}{*}{ Distance of patient's home and hospital in kilometers } & $<5$ & 350 & 39.41 \\
\hline & & $5-15$ & 242 & 27.22 \\
\hline & & $16-25$ & 79 & 8.93 \\
\hline & & $26-35$ & 51 & 5.71 \\
\hline & & $36-45$ & 44 & 4.90 \\
\hline & & $>45$ & 123 & 13.86 \\
\hline
\end{tabular}

TABLE 3: Respondents' main reason for emergency room visit in Nekemte, western Ethiopia, 2017.

\begin{tabular}{lccc}
\hline No. & Main reason for emergency room visit & Frequency & Percent \\
\hline 1 & Health provider advised to go & 233 & 26.20 \\
2 & The problem was so serious that other clinics cannot & 81 & 9.11 \\
3 & help & 181 & 20.38 \\
4 & Arrived by ambulance or other emergency vehicles & 207 & 23.30 \\
5 & The patient had no other place to go & 45 & 4.61 \\
6 & Emergency room is the closest provider & 62 & 7.04 \\
7 & Get most of care at the emergency room & 889 & 100.0 \\
Total & Unidentified reason & & \\
\hline
\end{tabular}

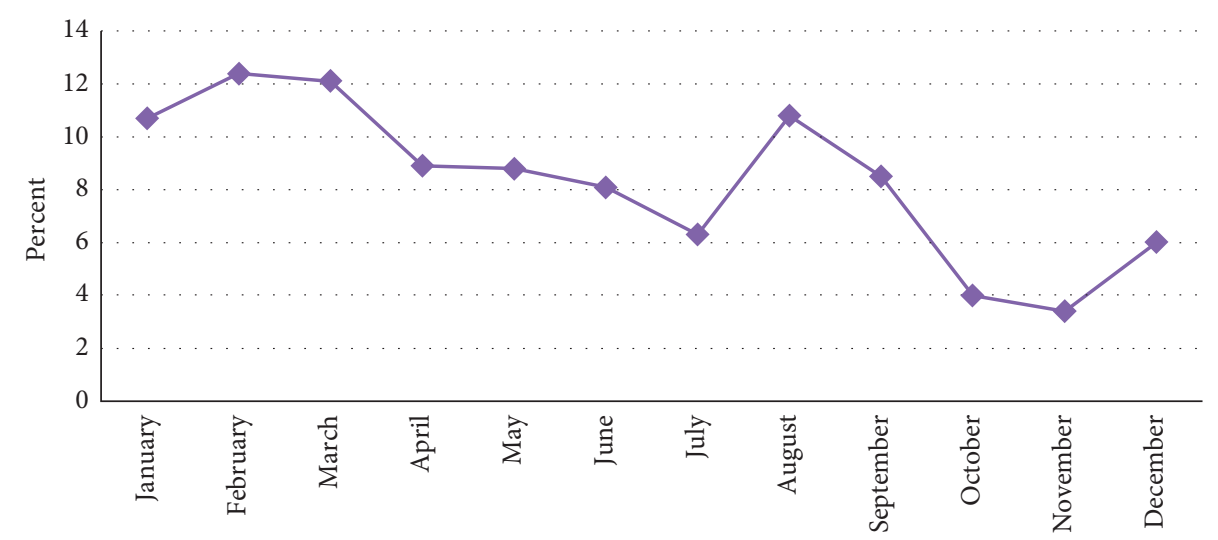

FIgURE 1: Patterns of adult emergency department admissions in Nekemte, western Ethiopia, 2017. 


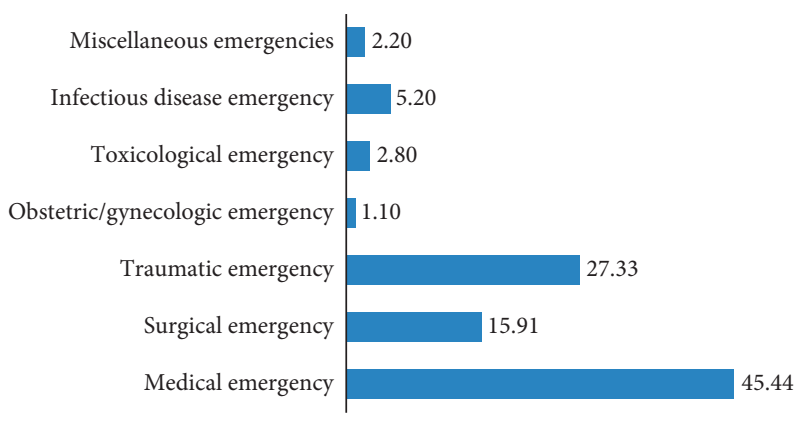

FIGURE 2: Major kinds of observed emergency conditions in the selected hospitals in Nekemte, western Ethiopia, 2017.

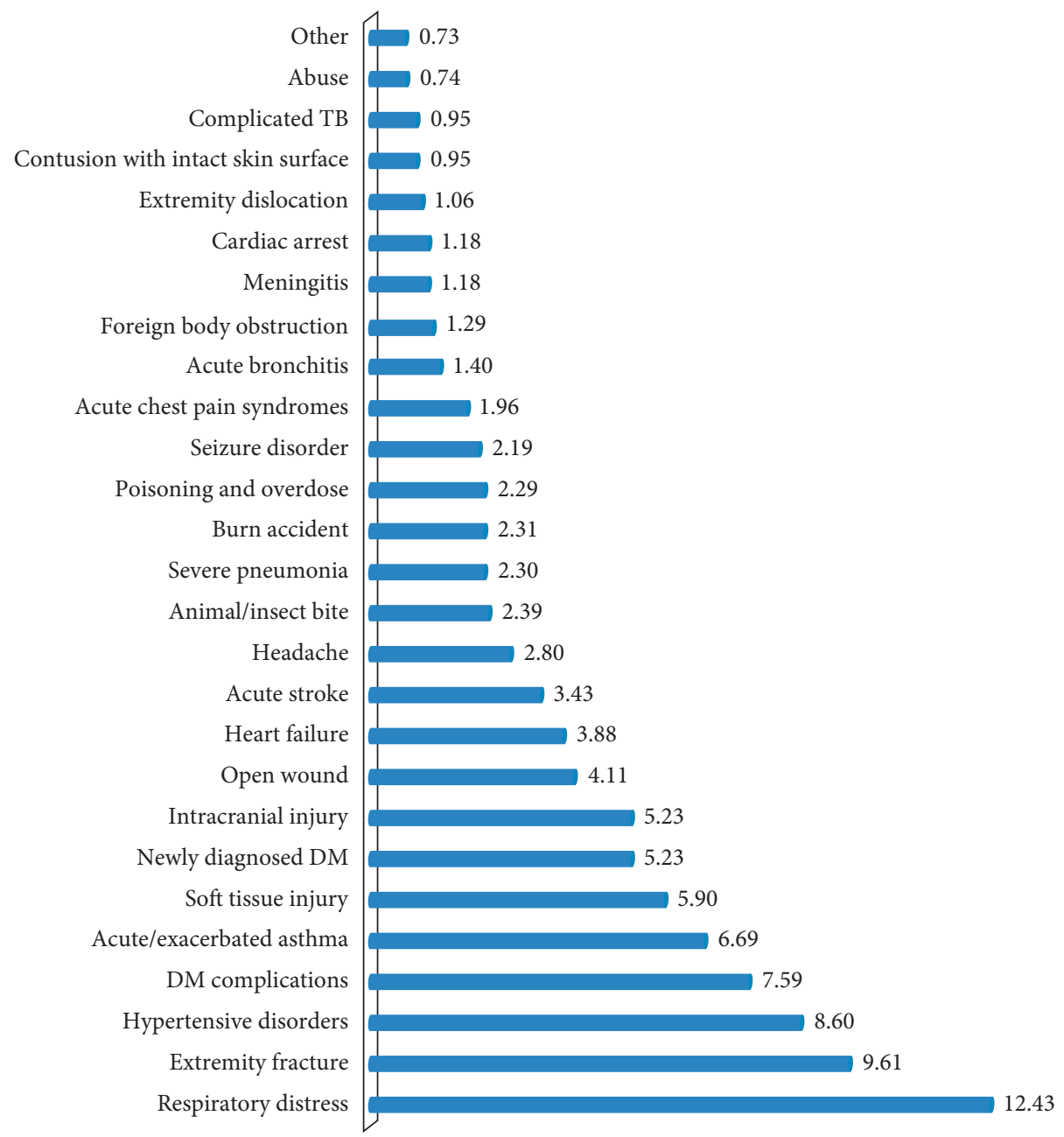

Figure 3: Leading causes of adult emergency department admission in the selected hospitals, Nekemte, Ethiopia, 2017.

ED admissions in this study were also found to be increasing progressively with age to reach peak at 15-24 years implying higher burden of diseases in the economically productive age group. Both findings are in line with similar studies conducted to determine the ED admission patterns in Nigeria $[2,5,10,12]$.

The decision to seek medical attention and the choice of healthcare provider are linked with the level of urgency of the complaint. Cases where there is little or no scope for choice refer to serious emergencies where immediate care is required
$[4,11]$. Also, the study explored respondents' relevant reasons of emergency room visits. While one-fourth (20.4\%) of them arrived by ambulances (without identifying reason), only 40 (4.5\%) of them visited the ED because they believe they get appropriate care at emergency rooms. About 23.6\% of the patients visited the hospitals because they had no other place to go. A similar study done by Gindi et al. to assess emergency room utilization among adults aged 18-64 years found that about $79.7 \%$ of adults have visited the emergency room due to lack of access to other providers. Another similar study 
TABLE 4: Identified medical emergencies as leading causes of emergency room admission, Nekemte, Ethiopia, 2017.

\begin{tabular}{lcc}
\hline Forms of medical emergencies & Frequency & Percent \\
\hline Cardiovascular $(N=257)$ & 12 & 4.63 \\
Acute chest pain syndromes & 71 & 27.62 \\
Hypertensive disorders & 29 & 11.22 \\
Heart failure & 140 & 54.41 \\
Shock & 5 & 1.90 \\
Cardiac arrest & 5 \\
\hline Neurology $(N=172)$ & 25 \\
Meningitis & 14 \\
Stroke & 11 \\
Seizure disorder & 117 \\
Headache & & 2.90 \\
Unconsciousness (coma) & 105 \\
Respiratory $(N=192)$ & 3 \\
Respiratory distress & 54 \\
Foreign body obstruction & 5 \\
Asthma & 15 \\
COPD & 7 \\
Severe pneumonia & 8.11 \\
Bronchitis & 6.31 \\
Complicated TB & 3 \\
\hline Endocrine $(N=96)$ & 68.00 \\
Diabetes mellitus & 54.60 \\
DM complications & 34 \\
\hline
\end{tabular}

TABle 5: Emergency room admission due to traumatic and toxicologic emergencies, in Nekemte, western Ethiopia, 2017.

\begin{tabular}{lcc}
\hline & Frequency & Percent \\
\hline Forms of traumatic injury $(N=483)$ & 3 & 0.65 \\
Contusion with intact skin surface & 47 & 9.71 \\
Soft tissue injury & 41 & 8.40 \\
Intracranial injury & 80 & 16.50 \\
Fracture & 4 & 0.81 \\
Dislocation & 6 \\
Foreign body obstruction & 69 \\
Burn & 37 \\
Falling accident & 99 \\
Road traffic accident & 6 \\
Machinery injury & 72 \\
Fighting & 14 \\
Other physical abuses & 5 \\
Sexual abuse & & 14.22 \\
Toxicology $(N=33)$ & 7.61 \\
Suicide & 12 \\
Human bites & 3 \\
Animal bites & 10.41 \\
Insect bites & 1.22 \\
Organophosphate poisoning & 14.90 \\
Carbon monoxide poisoning & 3 \\
Drug overdose & 18 \\
Unidentified & 2 & 2.82 \\
\hline
\end{tabular}

indicated that more than $66.0 \%$ who visited the ED was due to seriousness of the problems. One study, on the contrary, found that more than one-half of adults who have visited the emergency room was because of their perception that only the hospitals could provide help [3, 6, 9].

The admission patterns in the emergency room may reflect the actual burden of diseases in the immediate environment which also helps the health facilities to have a sound plan. In this study, the number of adult ED admissions per month was variable with peak admissions in the month of February and the lowest admission was in the month of November. We found that medical emergencies were found to be more frequent $(45.4 \%)$ causes of adult ED admissions followed by traumatic emergencies (27.3\%). The 


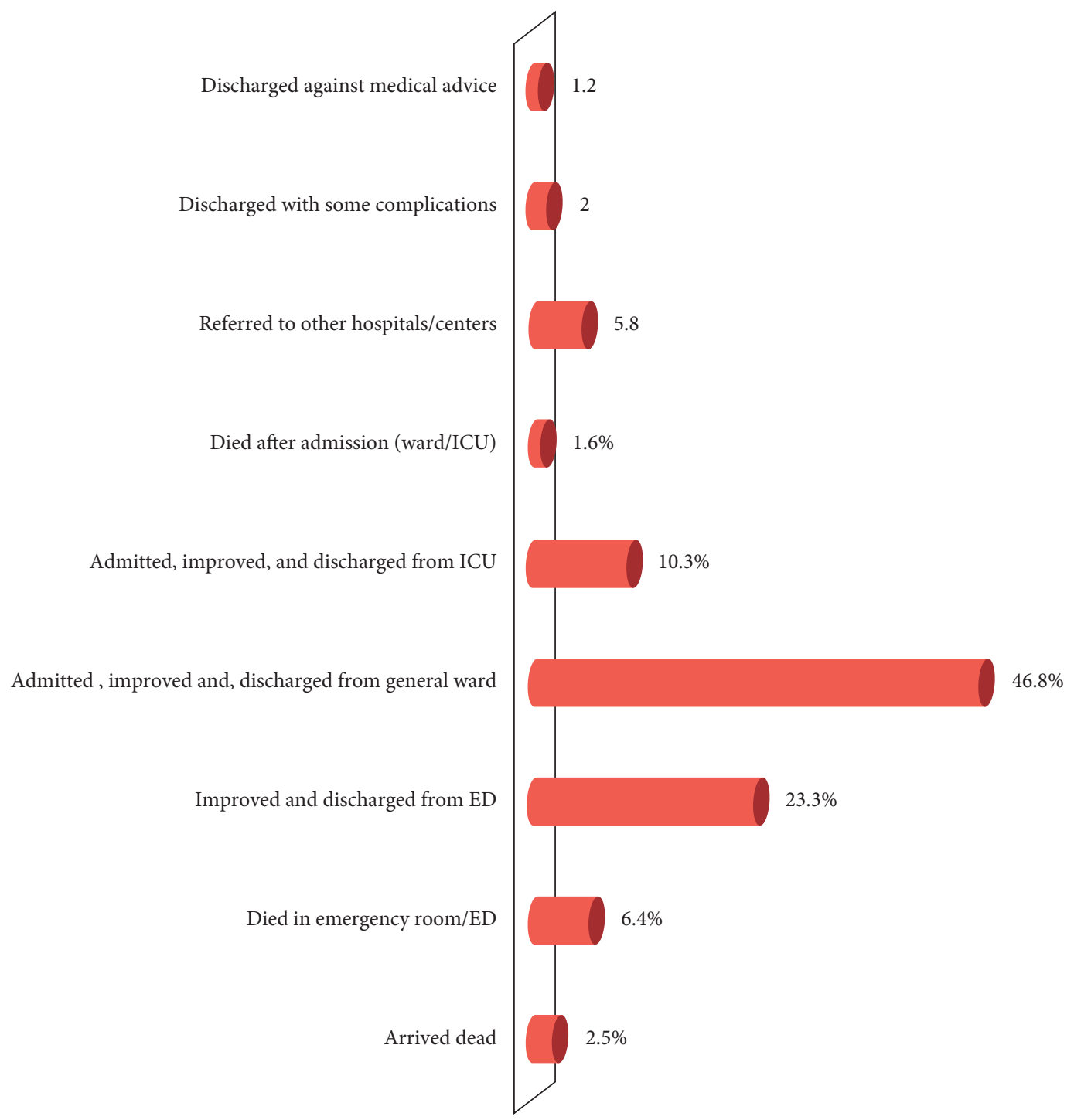

FIgURE 4: Distribution of respondents by their consequences of emergency department visits in Nekemte, western Ethiopia, 2017.

findings are in line similar other studies with little disparity from the study conducted at the University of Harcourt Teaching Hospital, in Nigeria which showed that only $17.3 \%$ (lower than $45.4 \%$ of this study) had medical emergencies $[3,6-11,13,14]$. The difference could be indicative of the rising epidemics of noncommunicable diseases in the study area related with the lifestyle changes.

The outcome of patients admitted to adult ED was found to vary with patients' demographic and clinical characteristics. Overall, among patients who visited ED of the selected hospitals in this study, about $8.5 \%$ died $(2.5 \%$ arrived dead, $6.4 \%$ died in ED, and the remaining $1.6 \%$ died after ward/ ICU admission). Out of all patients presented to the selected hospital in the area, vast majority (90.9\%) of them have survived after receiving treatment. The final outcome has not been identified in about $1.5 \%$ of patients due to referral and discharge against medical advice (DAMA). The ED mortality rate $(8.5 \%)$ in this study is much greater than the finding of similar study conducted in Addis Ababa. The observed discrepancy might have been due to differences in the standard of emergency department care between the two areas. Similarly, the mean length of stay in hospitals is much longer than what has been reported in Addis Ababa and consistent with studies conducted in other similar settings $[8,15,16]$.

This study has also revealed that impairment of breathing in about $37 \%$ followed by circulatory compromises in nearly $30 \%$ the emergency patients was observed as life-threatening problems. This is in line with the report found from UK, Nigeria, and similar other surveys but with slight variation with the study done in Ethiopia $[9,17,18]$.

\section{Conclusions}

This study showed the selected hospitals received mixed cases of emergency conditions which also ended up with significant proportion of adult death. The admission rate was found to be varying with seasonal difference. The outcome of patients admitted to adult ED was found to vary with patients' demographic and clinical characteristics. Higher 
proportion of the cases required admissions to the wards/ ICUs implying the seriousness of the encountered emergencies. A need for action to improve the readiness of existing emergency room services and investing further on standardizing and organizing prehospital services at the community level.

$\begin{array}{ll}\text { Abbreviations } \\ \text { AGE: } & \text { Acute gastroenteritis } \\ \text { CCU: } & \text { Critical care unit } \\ \text { CHF: } & \text { Congestive heart failure } \\ \text { DAMA: } & \text { Discharge against medical advice } \\ \text { DKA: } & \text { Diabetic ketoacidosis } \\ \text { ED: } & \text { Emergency department } \\ \text { ENT: } & \text { Ear nose throat } \\ \text { ICU: } & \text { Intensive care unit } \\ \text { NCD: } & \text { Noncommunicable disease } \\ \text { RTA: } & \text { Road traffic accident } \\ \text { SSA: } & \text { Sub-Saharan Africa } \\ \text { UK: } & \text { United Kingdom. }\end{array}$

\section{Data Availability}

The data used to support the findings of this study are available from the corresponding author upon request.

\section{Additional Points}

Limitation. As this was an institution-based study, the research did not know the fate of patients who have not visited the selected health facilities. In addition, the study did not identify the final outcomes of patients who were either referred to other facilities or discharged against medical advice.

\section{Conflicts of Interest}

The authors declare that they have no conflicts of interest of any form.

\section{Authors' Contributions}

Ashenafi Habte has designed and developed the research concept and involved in supervision of data collection process, statistical analysis, and preparation of the final document. Birhanu Yadecha and Getahun Fetensa have helped with research tool preparations and supervising data collection. Thanasekaran Palanichamy has involved in data analysis and revision of the final manuscript.

\section{Acknowledgments}

We would like to acknowledge Wollega University for funding the research data collection of this research. We would also like to extend our heartfelt gratitude to our study participants for their cooperation in responding the interview whilst they were in a physical and emotional suffering. Wollega University has funded this research only for data collection.

\section{References}

[1] O. E. Chukwuemeka, E. A. Christian, A. K. Uma, A. M. Chidiegwu, T. N. Sunday, and I. Chika, "Pattern of medical admissions in a tertiary health centre in abakaliki south-east Nigeria," Journal of Biology Agriculture and Healthcare, vol. 3, no. 12, 2013.

[2] A. J. Forster, I. Stiell, G. Wells, A. J. Lee, and C. van Walraven, "The effect of hospital occupancy on emergency department length of stay and patient disposition," Academic Emergency Medicine, vol. 10, no. 2, pp. 127-133, 2003.

[3] O. S. Ogah, R. O. Akinyemi, A. Adesemowo, and E. I. Ogbodo, "A two-year review of medical admissions at the emergency unit of a Nigerian tertiary health facility," African Journal of Biomedical Research, vol. 15, no. 1, pp. 59-63, 2012.

[4] W.-P. Goh, H.-F. Han, U.-C. Segara, G. Baird, and A. Lateef, "Acute medical unit: experience from a tertiary healthcare institution in Singapore," Singapore Medical Journal, vol. 59, no. 10, pp. 510-513, 2018.

[5] M. Z. Karim, E. L. Hansen, B. U. Ahmad, and S. Lahiry, “A retrospective study of illness and admission pattern of emergency patients utilizing a corporate hospital in Dhaka, Bangladesh: 2006 2008," ORION Medical Journal, vol. 32, no. 2, pp. 650-653, 2009.

[6] R. M. Gindi, R. A. Cohen, and W. K. Kirzinger, Emergency Room Use among Adults Aged 18-64: Early Release of Estimates from the National Health Interview Survey, JanuaryJune 2011, National Center for Health Statistics, Hyattsville, MD, USA, 2012.

[7] A. B. Belayneh, H. Teklie, M. Tadesse et al., "Pattern and trend of medical admissions of patients of chronic non-communicable diseases in selected hospitals in Addis Ababa, Ethiopia," American Scientific Research Journal for Engineering, Technology, and Sciences (ASRJETS), vol. 13, no. 1, pp. 34-48, 2015.

[8] B. M. Taye, M. O. Yassin, and Z. T. Kebede, "Quality of emergency medical care in Gondar University Referral Hospital, Northwest Ethiopia: a survey of patients' perspectives," BMC Emergency Medicine, vol. 14, no. 1, 2014.

[9] J. O. Ogunmola, Y. O. Oladosu, M. A. Olamoyegun, and L. M. Ayodele, "Mortality pattern in adult accident and emergency department of a tertiary health centre situated in a rural area of developing country," IOSR Journal of Dental and Medical Sciences (IOSR-JDMS), vol. 5, no. 2, pp. 12-15, 2013.

[10] D. D. A. Akpa, D. D. Altraide, P. C. Emem-Chioma, and I. S. Wokoma, "Profile and outcome of medical emergencies in a tertiary health institution in port Harcourt, Nigeria," The Nigerian Health Journal, vol. 13, no. 1, 2013.

[11] I. Krakau and E. Hassler, "Provision for clinic patients in the ED produces more nonemergency visits," The American Journal of Emergency Medicine, vol. 17, no. 1, pp. 18-20, 1999.

[12] D. Bell, A. Lambourne, F. Percival, A. A. Laverty, and D. K. Ward, "Consultant input in acute medical admissions and patient outcomes in hospitals in England: a multivariate analysis," PLoS One, vol. 8, no. 4, Article ID e61476, 2013.

[13] H. R. Sawe, J. A. Mfinanga, S. J. Lidenge et al., "Disease patterns and clinical outcomes of patients admitted in intensive care units of tertiary referral hospitals of Tanzania," BMC International Health and Human Rights, vol. 14, no. 1, p. 26, 2014. 
[14] R. L. Gardner, U. Sarkar, J. H. Maselli, and R. Gonzales, "Factors associated with longer ED lengths of stay," The American Journal of Emergency Medicine, vol. 25, no. 6, pp. 643-650, 2007.

[15] N. J. James, R. Hussain, A. Moonie, D. Richardson, and W. S. Waring, "Patterns of admissions in an acute medical unit: priorities for service development and education," Acute Medicine, vol. 11, no. 2, pp. 74-80, 2012.

[16] O. E. Anthony and A. G. S. John, "Medical causes of admissions to hospital among adults in Africa: a systematic review," Global Health Action, vol. 6, no. 1, p. 19090, 2013.

[17] N. Tang, J. Stein, R. Y. Hsia, J. H. Maselli, and R. Gonzales, "Trends and characteristics of US emergency department visits, 1997-2007," JAMA, vol. 304, no. 6, pp. 664-670, 2010.

[18] T. C. Garcia, A. B. Bernstein, and M. A. Bush, "Emergency department visitors and visits: who used the emergency room in 2007?," NCHS Data Brief, vol. 38, no. 38, pp. 1-8, 2010. 


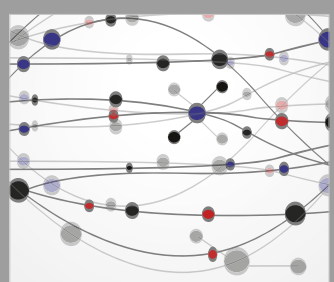

The Scientific World Journal
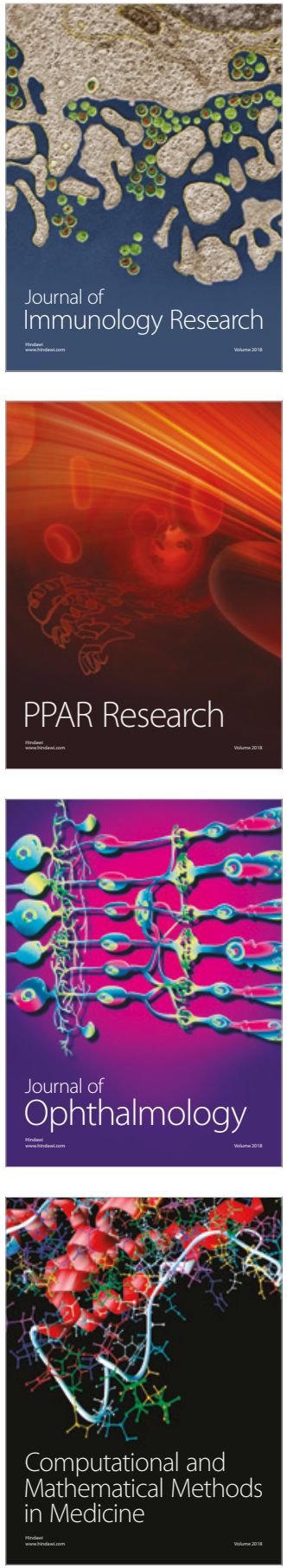

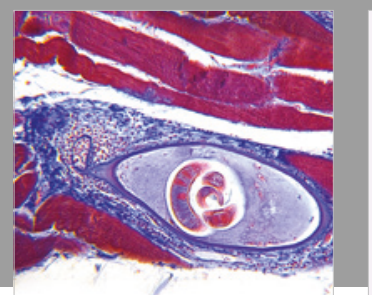

Gastroenterology Research and Practice

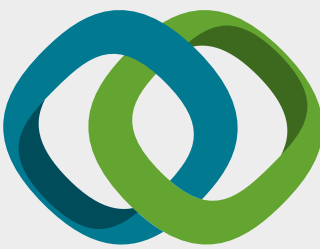

\section{Hindawi}

Submit your manuscripts at

www.hindawi.com
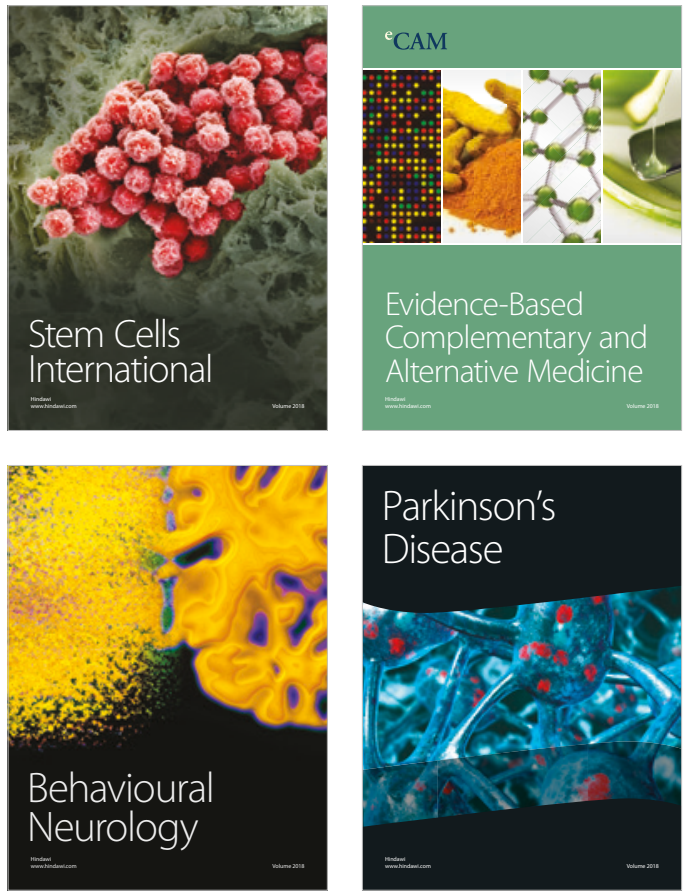

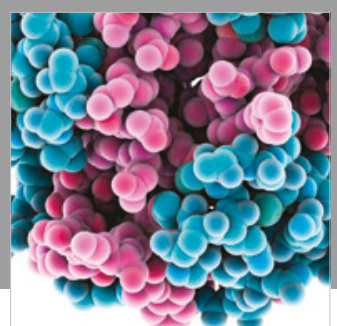

ournal of

Diabetes Research

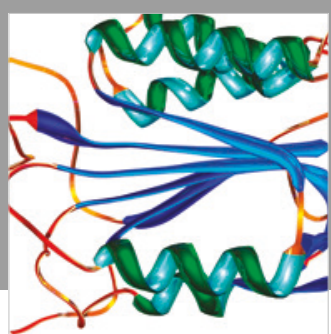

Disease Markers
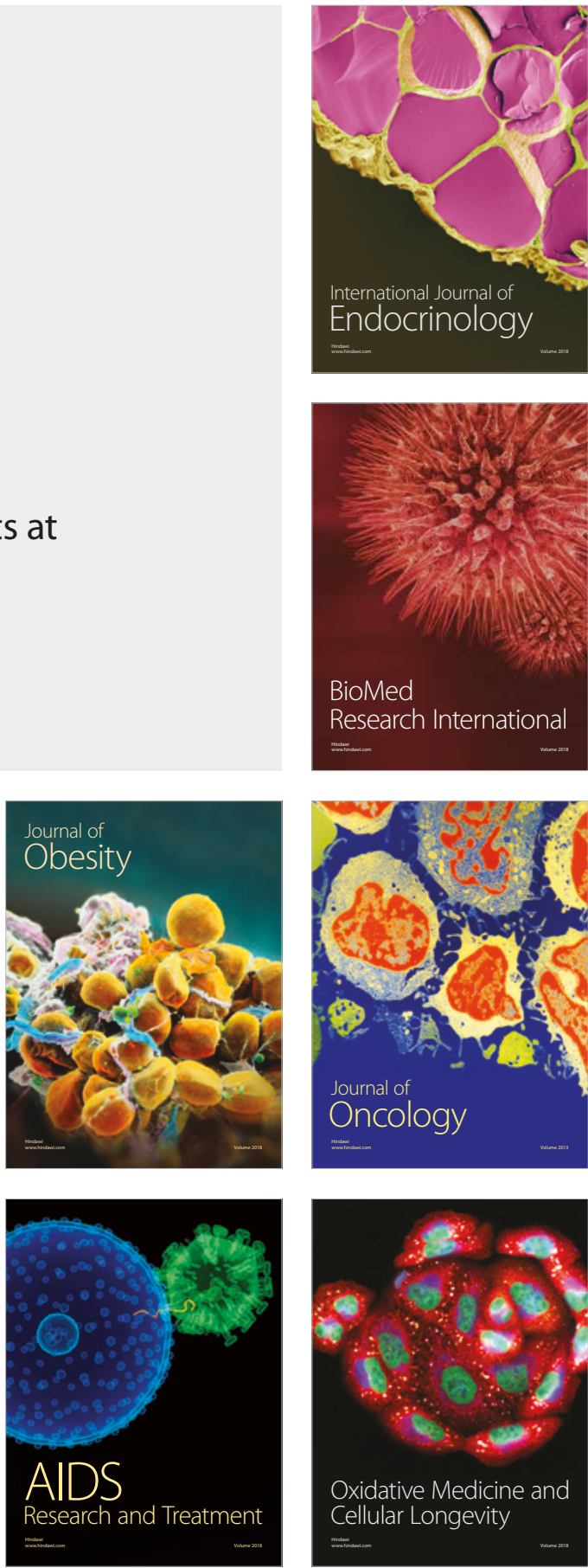